\title{
The impact of human land use and landscape productivity on population dynamics of red fox in southeastern Norway
}

\author{
Torfinn Jahren ${ }^{1} \cdot$ Morten Odden $^{1} \cdot$ John D. C. Linnell ${ }^{2} \cdot$ Manuela Panzacchi $^{2}$
}

Received: 12 August 2019 / Accepted: 1 April 2020 / Published online: 17 April 2020

(C) The Author(s) 2020

\begin{abstract}
In the boreal forest, the red fox (Vulpes vulpes) is a key species due to its many strong food web linkages and its exploitation of niches that form in the wake of human activities. Recent altitudinal range expansion and a perceived population increase have become topics of concern in Scandinavia, primarily due to the potential impacts of red foxes on both prey and competitor species. However, despite it being a common species, there is still surprisingly little knowledge about the temporal and spatial characteristics of its population dynamics. In this study, we synthesized 12 years of snow-track transect data covering a $27,000-\mathrm{km}^{2}$ study area to identify factors associated with red fox distribution and population dynamics. Using Bayesian hierarchical regression models, we evaluated the relationships of landscape productivity and climate gradients as well as anthropogenic subsidies with an index of red fox population size and growth rates. We found that landscapes with high human settlement density and large amounts of gut piles from moose (Alces alces) hunting were associated with higher red fox abundances. Population dynamics were characterized by direct density-dependent growth, and the structure of density dependence was best explained by the amount of agricultural land in the landscape. Population equilibrium levels increased, and populations were more stable, in areas with a higher presence of agricultural lands, whereas density-dependent population growth was more prominent in areas of low agricultural presence. We conclude that human land use is a dominant driver of red fox population dynamics in the boreal forest. We encourage further research focusing on contrasting effects of anthropogenic subsidization on predator population carrying capacities and temporal stability, and potential impacts on prey dynamics.
\end{abstract}

Keywords Density dependence $\cdot$ Human land use $\cdot$ Landscape ecology $\cdot$ Population dynamics $\cdot$ Red fox

\section{Introduction}

Human land use has dramatically altered the structure and dynamics of natural habitats in biomes across the world (Walther et al. 2002; Foley et al. 2005). Effects of human land use on species distribution and abundance vary in their complexity and direction. Direct effects of human influence may

Communicated by: Rafał Kowalczyk

Torfinn Jahren

Torfinn.jahren@inn.no

1 Faculty of Applied Ecology, Agricultural Sciences and Faculty of Applied Ecology, Agricultural Sciences and Biotechnology, Inland Norway University of Applied Sciences, 400,

2418 Elverum, Norway

2 Norwegian Institute for Nature Research, 5685, Torgarden, 7485 Trondheim, Norway be inevitable outcomes of habitat change (Andrén 1994) and resource management (e.g., Milner et al. 2006) or indirect consequences mediated through changes in community structure (e.g., Prugh et al. 2009). A matter of concern is an observed large-scale and long-term increase in the number and distribution of generalist predators, for example, the red fox (Vulpes vulpes) in Europe (e.g., Vos 1995; Prugh et al. 2009; Selås et al. 2011; Baines et al. 2016), the feral cat (Felis catus) in Australia (Fancourt et al. 2015), or the fisher (Pekania pennanti) in North America (Lapoint et al. 2015). Several ultimate explanations for the increase in generalist predator populations have been discussed, and in the context of our study, findings about the potential role of land use practices are especially relevant (Christiansen 1979; Henttonen 1989; Selås and Vik 2006). Additionally, the role of climate change and mesopredator release have received attention (e.g., Bartoń and Zalewski 2007; Prugh et al. 2009; Elmhagen et al. 2015). These are complementary hypotheses and they have been used in the above mentioned studies to explain increased 
carrying capacity of red fox populations due to increased resource availability or less intra-guild predation.

Opportunistic and facultative species like the red fox that take advantage of available foods ranging from berries to meat and human waste may successfully exploit niches that form in the wake of human activities. This may subsequently have detrimental effects on competitor- and prey species like pine marten (Martes martes) in the forest or arctic foxes (Vulpes lagopus) in alpine regions (Frafjord et al. 1989; Hersteinsson and MacDonald 1992; Lindstrom et al. 1994; Smedshaug et al. 1999; Kämmerle et al. 2017). Diverse and strong food web linkages of red foxes in the boreal forests have been demonstrated via both experimental and correlative predation studies on roe deer (Capreolus capreolus) and other prey species like grouse (Tetraonidae) and mountain hare (Lepus timidus) (Marcström et al. 1988; Lindstrom et al. 1994; Kauhala et al. 2000; Panzacchi et al. 2009).

The red fox is a very successful habitat generalist, and its distribution range is the largest among carnivores (Hersteinsson and MacDonald 1992). Locally, however, red foxes can turn into specialists and select mosaic landscapes (Pulliainen 1981; Kurki et al. 1998; Güthlin et al. 2013) with relatively high prey densities (Cavallini and Lovari 1991; Panzacchi et al. 2008a; Henden et al. 2014; CarricondoSanchez et al. 2016) and such landscapes are often modified by humans. Human settlements will primarily provide red foxes with increased scavenging opportunities (McKinney 2002; Vuorisalo et al. 2014). Secondary (i.e., indirect) effects from anthropogenic land use may be modulated via forestry and agricultural practices that cultivate cereals and grasses. Fields of grass and cereals create habitats for preferred prey (i.e., voles) (Christiansen 1979; Henttonen 1989; Panzacchi et al. 2010; Güthlin et al. 2013; Bogdziewicz and Zwolak 2013) and increase predation success by increasing the amount of habitat edges (Gorini et al. 2012 and references therein). The secondary effects of human land use distribute uniformly throughout the year and are therefore likely to increase overall carrying capacity. Additionally, a marked increase in ungulate abundances in Scandinavia during the last decades has increased the availability of carrion from natural mortality and gut piles (i.e., intestines, lungs, and stomach) left on site after big game hunting (Loison and Langvatn 1998; Stubsjøen et al. 2000; Gomo et al. 2017). Open season for, e.g., moose (Alces alces) starts in September and lasts until December. These are pulsed, but substantial, food resources that increase in abundance particularly preceding and during winter (Halpin and Bissonette 1988; Cagnacci et al. 2003; DeVault et al. 2003; Sidorovich et al. 2006; Needham et al. 2014; Gomo et al. 2017).

Red fox population densities in the boreal forest vary considerably among years according to the multi-annual population cycles of its main prey, microtine voles (Lindström 1982). This pattern is more profound with increasing latitude and altitude (Englund 1980a; Lindén 1988), and the degree of stability in the red fox population probably relates to both the availability of alternative prey in the low phase of the vole cycle and density-dependent, negative feedback mechanisms from predation on voles (Erlinge et al. 1983). Such negative feedback mechanisms may result from alternative prey sustaining high red fox population densities that, in turn, increase predation pressure on voles in the crash phase of the cycle.

Studies investigating red fox population performance rarely incorporate spatiotemporal variability and are therefore limited to either temporal or spatial inference. Whereas such studies are often valuable in identifying ecological factors and mechanisms in the dimension under study, they often fail to identify the complexity of spatiotemporal heterogeneity which is essential in understanding population and community dynamics (Thorson et al. 2015). We therefore aim to investigate factors potentially involved in the regulation of spatiotemporal variation in red fox abundance and population growth across a gradient of human influence on the landscape. To do this, we contrast potential effects of anthropogenic subsidies and land use to natural productivity gradients on red fox abundance and temporal variability in population growth structure. The bulk of literature on red fox spatial and temporal performance suggests that we can expect red fox population abundance to relate positively to the types of human land use practices that increase scavenging opportunities such as agricultural patches and settlements and, furthermore, that such human land use practices should stabilize the variability in population growth (e.g., Harris 1981; Gosselink et al. 2003; Vuorisalo et al. 2014), because red foxes can easily switch to more abundant prey in such areas if needed. Finally, we discuss potential mechanisms underlying the observed patterns as well as potential consequences of anthropogenic subsidization of generalist predators on the boreal forest ecosystem.

\section{Material and methods}

\section{Study area}

This study was conducted in Hedmark County, Norway, between 2003 and 2014 (Fig. 1). Hedmark $\left(27,400 \mathrm{~km}^{2}\right.$, of which $13,000 \mathrm{~km}^{2}$ is forest) has marked latitudinal productivity gradients. In the south, there are relatively high productive agricultural lowlands intermixed with large forested areas on low hills. Further north, there are deeper valleys, forest ridges, and mountains. In the north, agriculture and human settlements are confined to strips along the valley bottoms and the landscape is less productive. Agricultural land use categories were dominated by cereal production (64,000 ha) and grass production (41,000 ha) (Bjørlo et al. 2019). Similarly, the continental climate is milder in the south (annual mean temperature $4.76{ }^{\circ} \mathrm{C}$ ) than in the north (annual mean temperature 


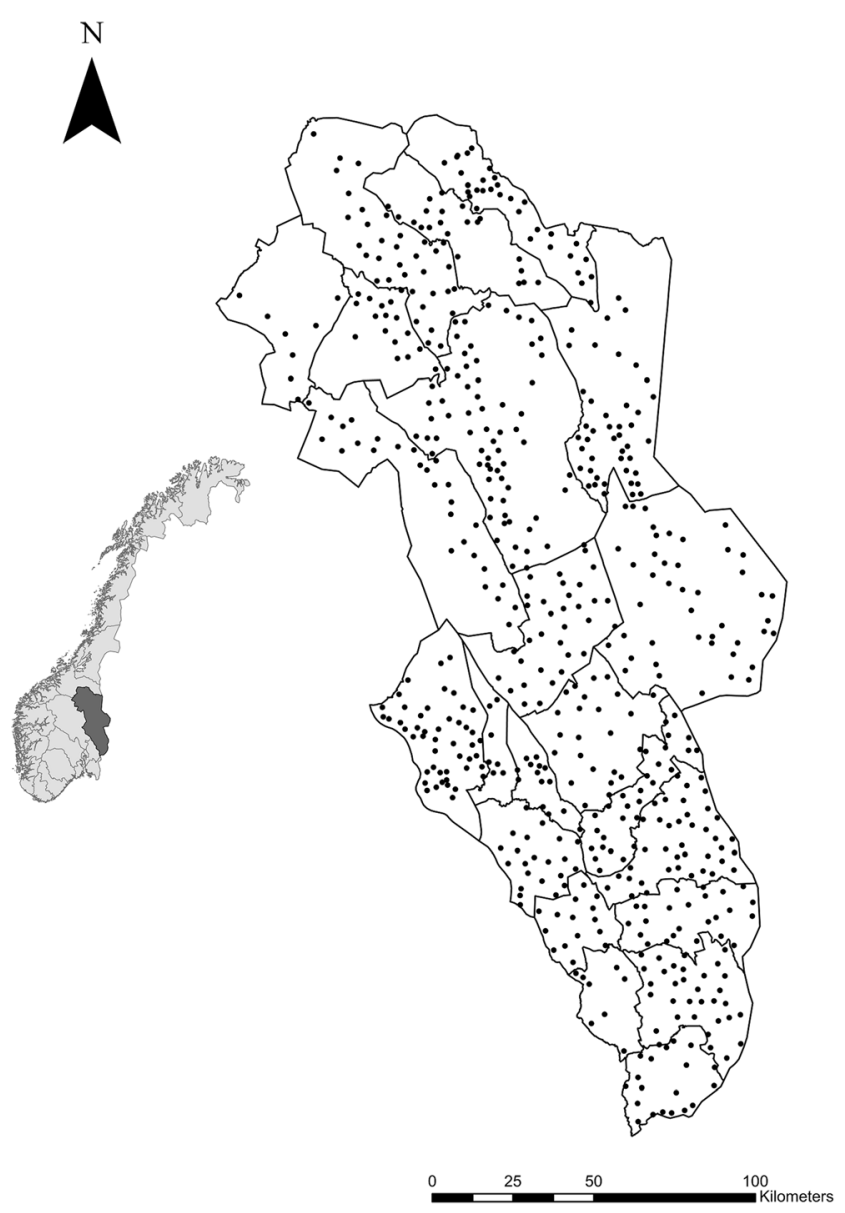

Fig. 1 Hedmark County in southeastern Norway with transect centroid points depicted as dots

$1.68^{\circ} \mathrm{C}$ ) (www.no.climate-data.org) and winter severity (i.e., snow depth and temperature) increases with a latitudinal as well as an altitudinal gradient. Forests are heavily managed for commercial timber production and primarily made up of conifers, dominated by Scots pine (Pinus sylvestris) and Norway spruce (Picea abies), but intermixed with deciduous species such as rowan (Sorbus aucuparia), gray alder (Alnus incana), aspen (Populus tremula), birch (Betula pubescens and $B$. pendula), and willow (Salix caprea). Municipalitywise, human population densities vary from 0.6 to 86 people $\mathrm{km}^{-2}$, with the lowest densities in the north. Red foxes are common throughout the county and annual hunting bags varied between 2160 and 4170 foxes during the study period (Statistics Norway 2016). In the study area, voles were non-cyclic prior to 2009. Since then, vole populations peaked in 2011 and 2014 (Breisjøberget et al. 2018). Potential predators of the red fox, e.g., Eurasian lynx (Lynx lynx) (Linnell et al. 1998) and golden eagle (Aquila chrysaetos) (Tjernberg 1981) occur throughout the county, whereas the low-density recolonizing gray wolf (Canis lupus) population is concentrated in the east and southeast (Odden et al. 2006; Ordiz et al. 2015; Tovmo et al. 2016). Other species that occur frequently in the study area and that are potential competitors to red fox throughout the year are pine marten (Storch et al. 1990), whereas European badgers (Meles meles) (Kauhala et al. 1998) are hibernating during winter.

\section{Red fox population index}

Snow tracking along 613 predefined transects averaging $2.95 \mathrm{~km}$ in length $(\mathrm{SD}=0.54)$ was organized by the Hedmark chapter of the Norwegian Association for Hunters and Anglers. Experienced volunteers conducted the fieldwork under favorable conditions (i.e., from 2 to 5 days after snowfall) in late January or early February each year between 2003 and 2014. The number of surveyed transects varied among years $($ mean $=391.7, \mathrm{SD}=54.9$, Table 1$)$. Transect layout was originally designed to monitor Eurasian lynx family groups, and transects were therefore situated below the treeline and across contour lines (Linnell et al. 2007). The number of crossing red fox tracks, transect length $(\mathrm{km})$, and days since last snowfall were reported for each transect survey. In total, 21,675 fox crossings were observed along 13,746 km of transect during the 12-year survey. Annual population index estimates were calculated as crossing tracks $\mathrm{km}^{-1} 24 \mathrm{~h}^{-1}$. In total, we obtained a population index estimate for 4700 transectyears. Snow-track surveys, as used here, give credible approximations of animal abundance and may be used to infer population dynamics of species (Thompson et al. 1989; Kurki et al. 1998; Kawaguchi et al. 2015), but it is important to acknowledge that such data hold information about both species density and activity. We further assume that activity patterns across the scale under study is not asymmetric but relatively homogenous. This is a realistic assumption given the spatial extent at which, e.g., red fox home range size varies (Walton et al. 2017). Nevertheless, the transect data ultimately reflect predation pressure by red fox as perceived by prey species across the landscape (Kurki et al. 1998).

\section{Red fox temporal variation}

Not all individual transects were complete 12-year time-series because of zero observations or they were not surveyed. The presence of zero observations constitutes a problem when doing time-series analysis because of, e.g., logarithmic transformations and calculation of population growth rates. To amend both zero observations and years not surveyed, individual transects were pooled into 300 transect groups based on proximity by using the spatstat and raster libraries in R (Baddeley et al. 2016; Hijmans 2016). With the pooling procedure, snow-track data and offsets were added whereas covariates were averaged. These transect groups then constituted new individual time-series for investigations of temporal variation in the red fox population. Consequently, after grouping, transect groups had longer sequences of monitoring and fewer 
Table 1 Annual number of transects surveyed and transect density

\begin{tabular}{lllllll}
\hline Year & 2003 & 2004 & 2005 & 2006 & 2007 & 2008 \\
Number of transects & 360 & 434 & 459 & 472 & 367 & 347 \\
Transects per $100 \mathrm{~km}^{-2}$ total area & 1.31 & 1.58 & 1.68 & 1.72 & 1.34 & 1.27 \\
Transects per $100 \mathrm{~km}^{-2}$ forested area & 2.77 & 3.34 & 3.53 & 3.63 & 2.82 & 2.67 \\
Year & 2009 & 2010 & 2011 & 2012 & 2013 & 2014 \\
Number of transects & 415 & 430 & 403 & 354 & 391 & 268 \\
Transects per $100 \mathrm{~km}^{-2}$ & 1.51 & 1.57 & 1.47 & 1.29 & 1.43 & 0.98 \\
Transects per $100 \mathrm{~km}^{-2}$ forested area & 3.19 & 3.31 & 3.10 & 2.72 & 3.01 & 2.06 \\
\hline
\end{tabular}

zero-observations. For zero counts (not to be confused with not surveyed) still remaining after grouping $(n=97)$, we added the smallest observable entity possible (Turchin 2003), which in our case was 1 crossing red fox track. Finally, because red fox populations in the southern boreal forest have previously been described as cyclic with a length of 3-4 years, each time-series should cover minimum one potential cycle. We therefore discarded segments of $<4$ years of consecutive monitoring and remaining segments were treated as 255 individual, complete time-series with 1781 timesteps of population index estimates (Supplementary material Appendix, Fig. 7).

\section{Habitat data}

Transects were related to predictor variables via the transect centroid point. These predictors included elevation, latitude, relative settlement density, and relative agricultural density (Fig. 2). Transect altitude was assessed via a digital terrain model (DTM) from The Norwegian Mapping Authority (The Norwegian Mapping Authority 2017). We expressed latitude as the UTM-north coordinate of the transect centroid

Fig. 2 From left to right: relative density of agricultural land, relative settlement density, and the digital elevation model used as predictors. From green to white indicate low to high values of the respective parameter

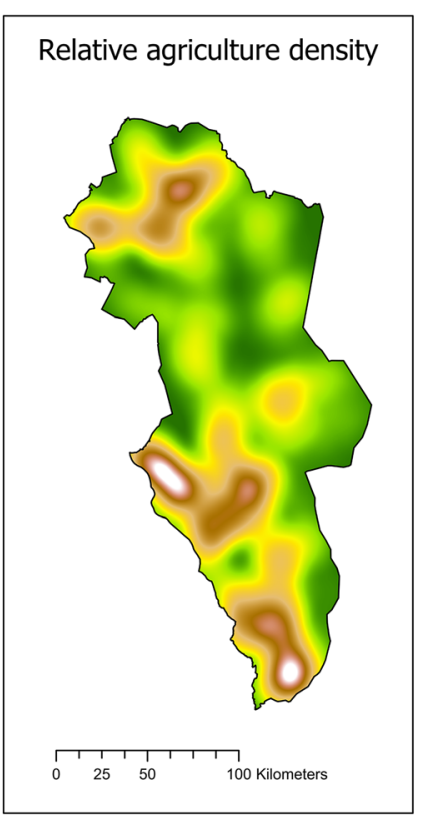

point. Land use maps (N250) (The Norwegian Mapping Authority 2017) were the basis for relative settlement and agricultural density estimates. We transformed houses to a point layer that was subsequently used to predict a planar kernel density map from which we extracted kernel values for each transect centroid point. Kernel bandwidth was estimated by Gaussian approximation (Silverman 1986). For relative density of agricultural land, we calculated the geometrical center of agriculture fields and predicted planar kernel density by using agricultural field size as $z$ value. Again, kernel density values were extracted to the transect centroid points.

The only predictor with spatiotemporal variation was number of moose culled per hectare of productive forest. This variable (hereafter "moose culled") was calculated for each municipality ( 351 to $3180 \mathrm{~km}^{2}$ large), as this was the smallest scale from which culling data was available. The annual number of moose culled per municipality was retrieved from Statistics Norway (Skara and Steinset 2016) and Hjorteviltregisteret (Miljødirektoratet 2016), whereas the extent of productive forest was derived from digital land use maps (N250) (The Norwegian Mapping Authority 2017). In

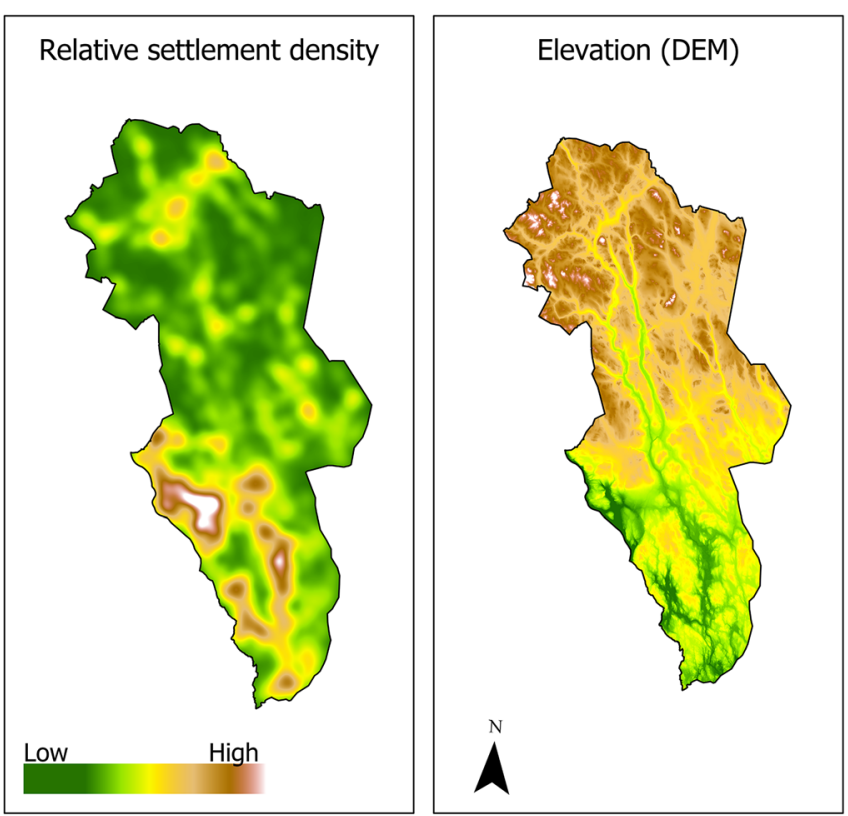


total, the annual bag of moose varied between 6164 and 8055 animals. Transect group predictors were the means of the transect predictor values prior to grouping. Development of planar kernel density predictions was done in ArcGIS (ESRI INC 2011).

\section{Statistical analyses}

We evaluated environmental and anthropogenic relationships to red fox population indices by modeling the population index (tracks $\mathrm{km}^{-1} 24 \mathrm{~h}^{-1}$ ) as a dependent variable in a hierarchical Bayesian linear model framework via the rethinking library (McElreath 2016) in R (R Core Team 2016). The red fox population index was formalized as a gamma-Poisson distribution with a log link function. The linear predictor was offset with the log of transect length $(\mathrm{km})$ and $\log$ of days since last snowfall, and we fitted municipality as a random effect (see the appendix for details on model components).

To describe and specify temporal variation in the red fox population, we first detrended all time-series with the fitted values from a linear model of the respective time-series. Then, each transect group with $>10$ time-steps $(n=58)$ was checked for cyclicity in the negative feedback processes via the partial rate correlation function (PRCF). The PRCF is quite similar to the partial auto correlation function, but it regresses the instantaneous rate of increase $\left(r_{t}=\ln \left(\frac{N_{t}}{N_{t-1}}\right)\right)$ on lagged population indices (Berryman and Turchin 2001). We did not detect any cyclic pattern in the negative feedback processes of population regulation by using Bartlett's criteria of significance. Furthermore, lag 1 from the partial rate correlation function (PRCF[1]) was the dominating order of feedback-delay indicating that direct density dependence was the dominating pattern in growth structure of the red fox population. Henceforth, we used the instantaneous rate of increase $(r)$ as a dependent variable in the model framework investigating spatiotemporal variation in population growth. These models were formalized as a Gaussian distribution with an identity link (see the appendix for details on model components).

We modeled both the population index and densitydependent growth as functions of linear terms. Each model of instantaneous rate of increase included the red fox population index at time $t_{-1}$ as part of an interaction with each predictor. This allowed us to investigate spatial variation in density dependence. The population index at time $t_{-1}$, however, was formalized as a second-order polynomial due to its curvilinear relationship to the instantaneous rate of increase. We fitted 20 and 11 a priori models for each dependent variable (population index and $r$ respectively). We specified simple models aiming at obtaining factorspecific information relating red fox population index and density-dependent growth to anthropogenic activity and natural productivity gradients.

Relative settlement and agricultural density, as well as elevation and latitude, were not paired in the same model due to collinearity $(r>0.6)$. All predictors were scaled to $z$ scores $(x$ - mean/2SD), and thus, intercepts and interactions were simpler to interpret (Gelman and Su 2016). Markov chain Monte Carlo sampling (MCMC) was specified to run at four chains across 6000 iterations and burn-in was set to 4000 iterations. We detected spatial autocorrelation in our dependent variable via the Moran's I test (Moran 1950). Spatial autocorrelation was handled by modeling varying intercepts as a function of squared distances between the random effects (i.e., between municipalities and transect groups for population index and growth models respectively) (McElreath 2016).

Fig. 3 Mean population index of red fox (tracks km $\left.{ }^{-1} 24 \mathrm{~h}^{-1}\right) \pm$ 2SE across transects in the study area (2003-2014)

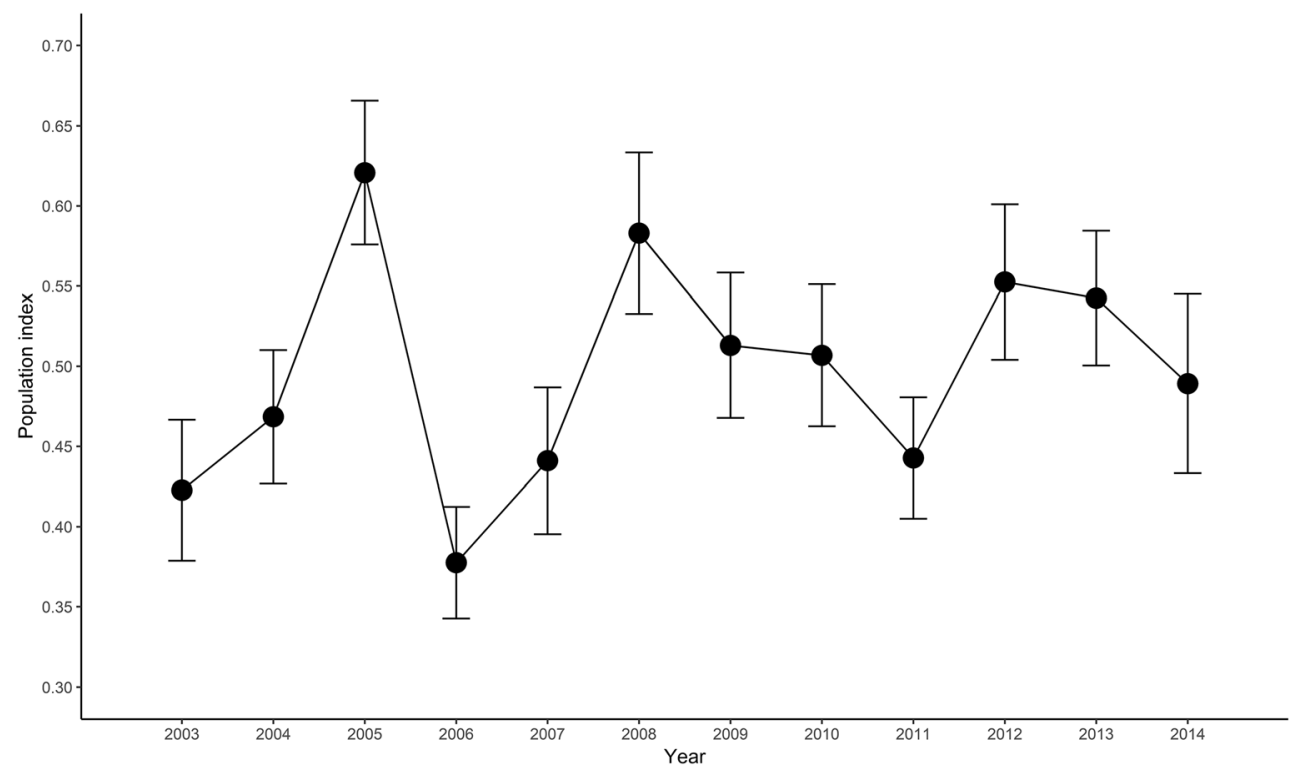


Table 2 Bayesian mixed effect regression models for red fox abundance ranked according to widely applicable information criterion (WAIC)

\begin{tabular}{lllll}
\hline Model & WAIC & $K$ & $\Delta$ WAIC & Weight \\
\hline Settlements + moose culled & $24,327.7$ & 38.8 & 0 & 0.82 \\
Elevation + settlements & $24,331.3$ & 40.3 & 3.7 & 0.13 \\
Settlements * moose culled & $24,334.6$ & 41.2 & 6.9 & 0.03 \\
Settlements * elevation & $24,336.3$ & 42.5 & 8.6 & 0.01 \\
Latitude + settlements & $24,337.7$ & 39.3 & 10.1 & 0.01 \\
Settlements & $24,338.2$ & 38.8 & 10.5 & 0 \\
Latitude * settlements & $24,342.3$ & 40.9 & 14.7 & 0 \\
Elevation + agriculture & $24,447.8$ & 45.0 & 120.2 & 0 \\
Elevation * agriculture & $24,452.5$ & 47.0 & 124.8 & 0 \\
Agriculture + moose culled & $24,457.6$ & 42.9 & 129.9 & 0 \\
Agriculture * moose culled & $24,467.6$ & 46.8 & 139.9 & 0 \\
Latitude + agriculture & $24,476.4$ & 44.6 & 148.7 & 0 \\
Agriculture & $24,477.6$ & 43.9 & 149.9 & 0 \\
Latitude * agriculture & $24,482.3$ & 46.1 & 154.6 & 0 \\
Elevation & $24,555.4$ & 47.5 & 227.7 & 0 \\
Moose culled & $24,622.2$ & 46.5 & 294.5 & 0 \\
Latitude + moose culled & $24,624.6$ & 48.3 & 296.9 & 0 \\
Latitude * moose culled & $24,630.1$ & 50.8 & 302.5 & 0 \\
Latitude & $24,640.1$ & 48.1 & 312.4 & 0 \\
Constant & $24,643.4$ & 46.8 & 315.8 & 0 \\
\hline
\end{tabular}

$\triangle W A I C$ is the change in WAIC relative to the highest ranking model, $K$ the number of parameters in the model, Weight is the Akaike model weight

\section{Model evaluation and selection}

We visually inspected Markov chains for failure to converge and no convergence issues were detected. All $\widehat{R}$ values were between 1 and 1.01. Relative model parsimony was assessed by WAIC (widely applicable information criterion) (Watanabe
2010) based on posterior likelihoods. We followed an information-theoretic approach when evaluating models, and hence, a combination of model weights (i.e., threshold $\triangle$ WAIC $<2$ ) and relative distance to the top model were criteria of inference. Parameter posterior predictions were averaged across models based on model weights, keeping all other fixed effects constant, and reported parameter predictions henceforth incorporate parameter uncertainty.

\section{Results}

Temporal variation in the population index of red fox in the study area varied between 2003 and 2014 with more variation earlier than later in the period (Fig. 3).

Evaluation of the population index models showed that the additive effect of settlement density and moose culled performed markedly better than any other model $\left(\mathrm{WAIC}_{w}=0.82\right) \quad$ (Supplementary material Appendix, Table 2). The positive relationship of settlement density to the red fox population index was quite strong, whilst the weaker, but positive, relationship of moose culled included a slope of zero (Fig. 4). Adding moose culled to settlement density greatly improved the model parsimony as compared to settlement density alone (Supplementary material Appendix, Table 4).

Whereas the mean population index from transect groups was generally concentrated around a few hotspots, absolute values of instantaneous rate of increase were more heterogeneously distributed (Fig. 5). The first-order (i.e., annual) density-dependent structure indicated a relatively strong degree of density dependence $(\beta=-1.33)$ (Supplementary material Appendix, Fig. 8). Median instantaneous rate of increase was 0.045 (mean $=0.027, \mathrm{SD}=0.025)$ and ranged between -3.62 and 3.68 (Supplementary material Appendix, Fig. 9).
Fig. 4 Model weighted predictions of red fox population index as a function of settlements (left) and moose culled ha ${ }^{-2}$ productive forest (right) whilst holding the other fixed effect constant. Shaded areas are $95 \%$ highest posterior density intervals
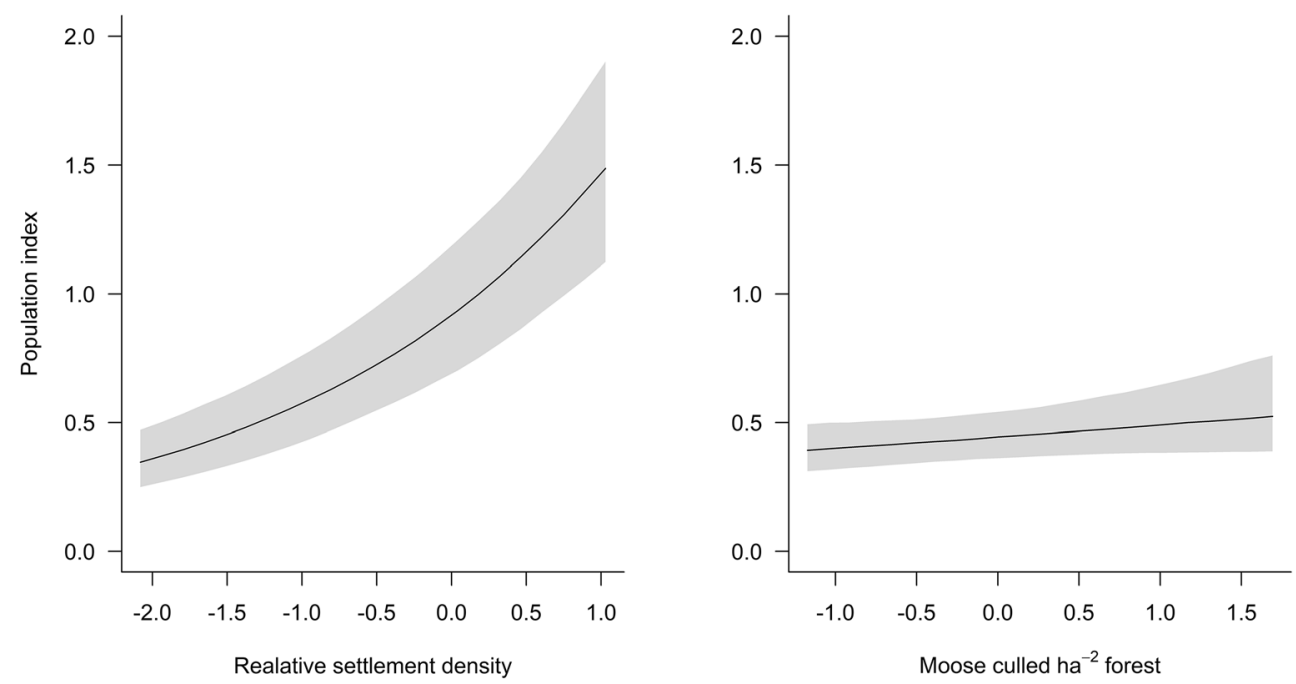
Mean population index
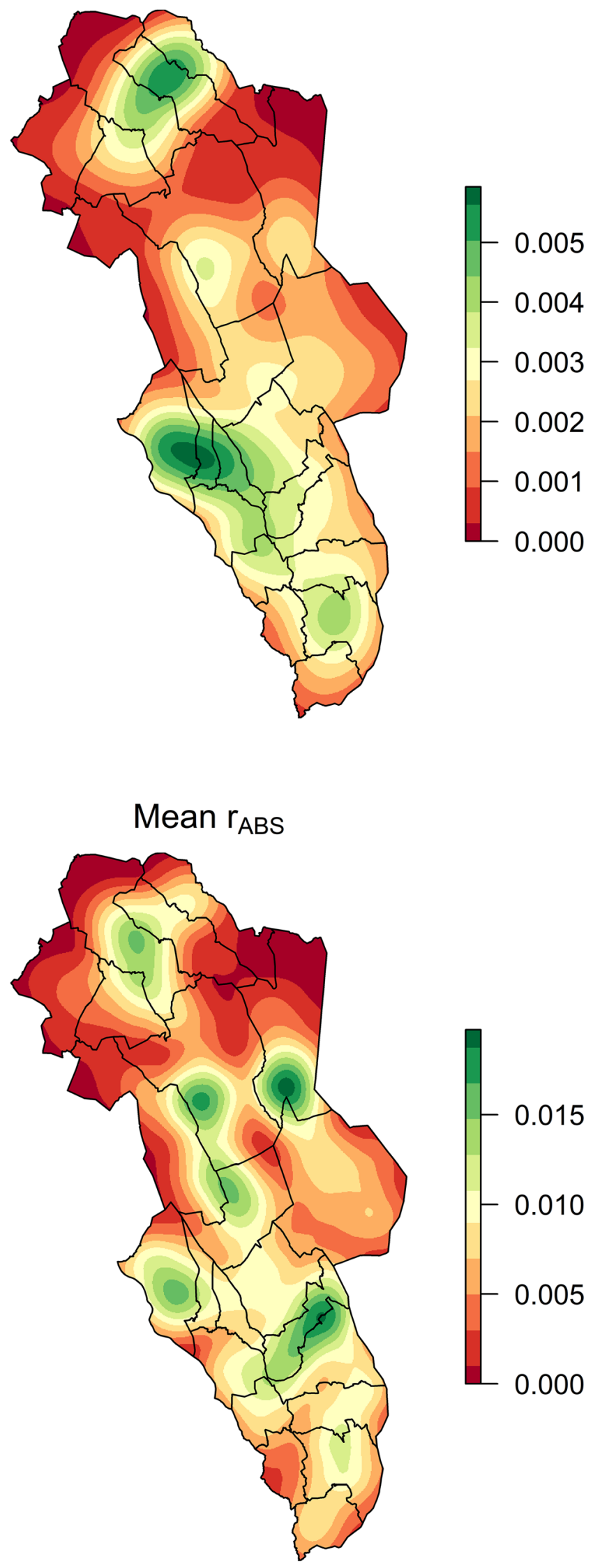

Fig. 5 Spatial variation in mean red fox population index (2003-2014) and instantaneous rate of increase (mean of absolute values 2003-2014) from the transect groups in Hedmark County

The best performing model of spatially explicit, first-order density-dependent growth was the interaction between the red fox population index and relative density of agricultural land in the landscape (Supplementary material Appendix, Tables 3 and 4). The density-dependent structure in the red fox population was asymmetric throughout the agricultural landscape indicating higher variability in the population index across areas with less agricultural land. Landscapes with more agriculture sustained a slightly higher equilibrium and an increasingly stable population index of red fox, as the equilibrium point (i.e., $r_{t}=0$ ) increased along the gradient from low to high proportions of agricultural fields in the landscape (Fig. 6).

\section{Discussion}

In this paper, we show that the spatiotemporal dynamics of red foxes are closely interrelated with human landscape modification and activities. The red fox population index related positively to relative settlement density and the density of moose culled from hunting. Furthermore, we found that negative feedback processes of first-order dynamics (i.e., direct density dependence) dominated the structure of temporal variation in the population index. An increase in the population index of one reduced the instantaneous rate of increase by 1.3, implying relatively strong density dependence. Overall, the equilibrium of the population index (i.e., $r_{t}=0$ ) increased and temporal variability around the equilibrium decreased in areas where agricultural practices (i.e., crop and grass production) was a dominating form of land use.

Positive relationships between fox abundance and human settlements have been observed earlier (e.g., Panek and Bresinski 2002). Human-dominated landscapes are attractive to red foxes primarily via anthropogenic subsidies in the form of increased scavenging opportunities on, e.g., garbage and road kills (Rosalino et al. 2010; Selås et al. 2010). Elevation was nonetheless included in the second best model, but other predictors representing climate and productivity gradients (e.g., latitude) were generally not ranked high. This implies that potential effects of settlements differ from those of landscape productivity and climate and, furthermore, that strong relationships between red fox indices and anthropogenic influence mask potential effects of natural productivity and climate gradients.

Although there was a positive relationship between moose culled and the red fox index, the relationship was weak. This is surprising given the multitude of forage and diet studies 
Table 3 Bayesian mixed effect regression models for red fox density dependence ranked according to widely applicable information criterion (WAIC)

\begin{tabular}{|c|c|c|c|c|}
\hline Model & WAIC & $K$ & $\Delta$ WAIC & weight \\
\hline Agriculture $*$ density^ 2 & 4119.1 & 156.3 & 0 & 0.62 \\
\hline Settlements $*$ density ${ }^{\wedge}$ & 4121.8 & 151.9 & 2.6 & 0.17 \\
\hline Agriculture $*$ density $2+$ moose culled & 4122.6 & 156.9 & 3.5 & 0.11 \\
\hline Settlements $*$ density ${ }^{\wedge}+$ moose culled & 4122.8 & 152.9 & 3.6 & 0.10 \\
\hline Density $^{\wedge} 2$ & 4151.9 & 167.1 & 32.7 & 0 \\
\hline Moose culled $*$ density 2 & 4159.1 & 170.0 & 39.9 & 0 \\
\hline Elevation $*$ density^2 & 4159.6 & 168.7 & 40.4 & 0 \\
\hline Elevation $*$ density ${ }^{\wedge} 2+$ moose culled & 4161.6 & 169.3 & 42.4 & 0 \\
\hline Latitude $*$ density $^{\wedge} 2+$ moose culled & 4161.8 & 169.8 & 42.6 & 0 \\
\hline Latitude $*$ density^2 & 4162.0 & 170.2 & 42.8 & 0 \\
\hline Constant & 5074.7 & 30.4 & 955.6 & 0 \\
\hline
\end{tabular}

$\triangle W A I C$ is the change in WAIC relative to the highest ranking model, $K$ the number of parameters in the model, Weight is the Akaike model weight identifying entrails, carrion, and carcass remains as important items in red fox diets (Halpin and Bissonette 1988; Jędrzejewski and Jędrzejewska 1992; Cagnacci et al. 2003; DeVault et al. 2003; Sidorovich et al. 2006; Panzacchi et al. 2008b; Needham et al. 2014). The inclusion of the moose culled term, however, greatly improved the relative model performance over settlements alone and moose culled thus explained a large proportion of the variance in the red fox index not accounted for by settlements. This specific pattern may be caused by the fact that offal from hunting is mainly available in a temporally narrow pulse during late autumn (Gomo et al. 2017). Additionally, as highlighted in several dietary studies, there is temporal variability in the importance of large herbivore remnants and carcasses. In Poland, deer carcasses from kills from large carnivores or other winter mortality were important buffer foods when voles were scarce (Jędrzejewski and Jędrzejewska 1992), whereas the importance of carcasses from semi-domesticated reindeer (Rangifer tarandus tarandus) was inversely related to lemming (Lemmus lemmus) abundance in northern Norway (Killengreen et al. 2011). As such, the degree of scavenging for carcasses probably interacts with varying accessibility to voles, either via their abundance or, e.g., snow cover (Willebrand et al. 2017). The impact of such alternative sources of foods to the red fox needs to be better understood, but they are probably improving body condition preceding winter and thus winter survival (Needham et al. 2014).

The observed range in the estimated instantaneous rate of increase was higher than in other reports (e.g., Hone 1999), and we propose two explanations for this pattern. Firstly, dispersal of highly mobile juvenile red foxes (Englund 1980b) as well as considerable flexibility in space use within home ranges (i.e., LoCoH 90 vs. MCP 100) (Walton et al. 2017) are innate components of the monitored population, and secondly, the fluctuating nature of the boreal forest ecosystem should yield high variation in birth and death rates (Lindström 1982). In systems with fluctuating resources (e.g., vole cycles in the boreal forest), these two mechanisms are entwined because red foxes may show an aggregative and/ or a demographic responses to spatiotemporal variability in resource distribution (Henden et al. 2010; McKinnon et al. 2013). It is worth noting that we cannot separate the two

Table 4 Parameter estimates for the best performing models explaining red fox abundance (top) and population growth (bottom). Credible intervals are given at the $95 \%$ level

\begin{tabular}{|c|c|c|c|c|c|c|c|c|c|c|c|c|}
\hline & \multicolumn{2}{|l|}{$\alpha$} & \multicolumn{2}{|l|}{$\beta 1$} & \multicolumn{2}{|l|}{$\beta 2$} & \multicolumn{2}{|l|}{$\beta 3$} & \multicolumn{2}{|l|}{$\beta 4$} & \multicolumn{2}{|l|}{$\beta 5$} \\
\hline & \multicolumn{2}{|l|}{ Intercept } & \multicolumn{2}{|c|}{ Settlement } & \multicolumn{4}{|c|}{ Moose culled } & & & & \\
\hline Abundance & -0.79 & & 0.47 & & 0.12 & & & & & & & \\
\hline \multirow[t]{2}{*}{$95 \%$ CI } & -0.88 & -0.7 & 0.03 & 0.41 & -0.02 & 0.27 & & & & & & \\
\hline & \multicolumn{2}{|l|}{ Intercept } & \multicolumn{2}{|l|}{ Agri } & \multicolumn{2}{|c|}{ Abundance } & \multicolumn{2}{|c|}{ Abundance $^{2}$} & \multicolumn{2}{|c|}{ Agri/abundance } & \multicolumn{2}{|c|}{ Agri/abundance $^{2}$} \\
\hline Growth & -0.11 & & 0.42 & & -1.93 & & 0.56 & & 0.5 & & -0.33 & \\
\hline $95 \% \mathrm{CI}$ & -0.26 & 0.04 & 0.3 & 0.53 & -2.07 & -1.8 & 0.48 & 0.66 & 0.28 & 0.72 & -0.51 & -0.16 \\
\hline
\end{tabular}


Fig. 6 Model weighted predictions of the interaction between agricultural land and red fox index $\left(N_{t-1}\right)$ on the instantaneous rate of increase in the red fox population. Red to green gradient depict negative to positive instantaneous rate of increase

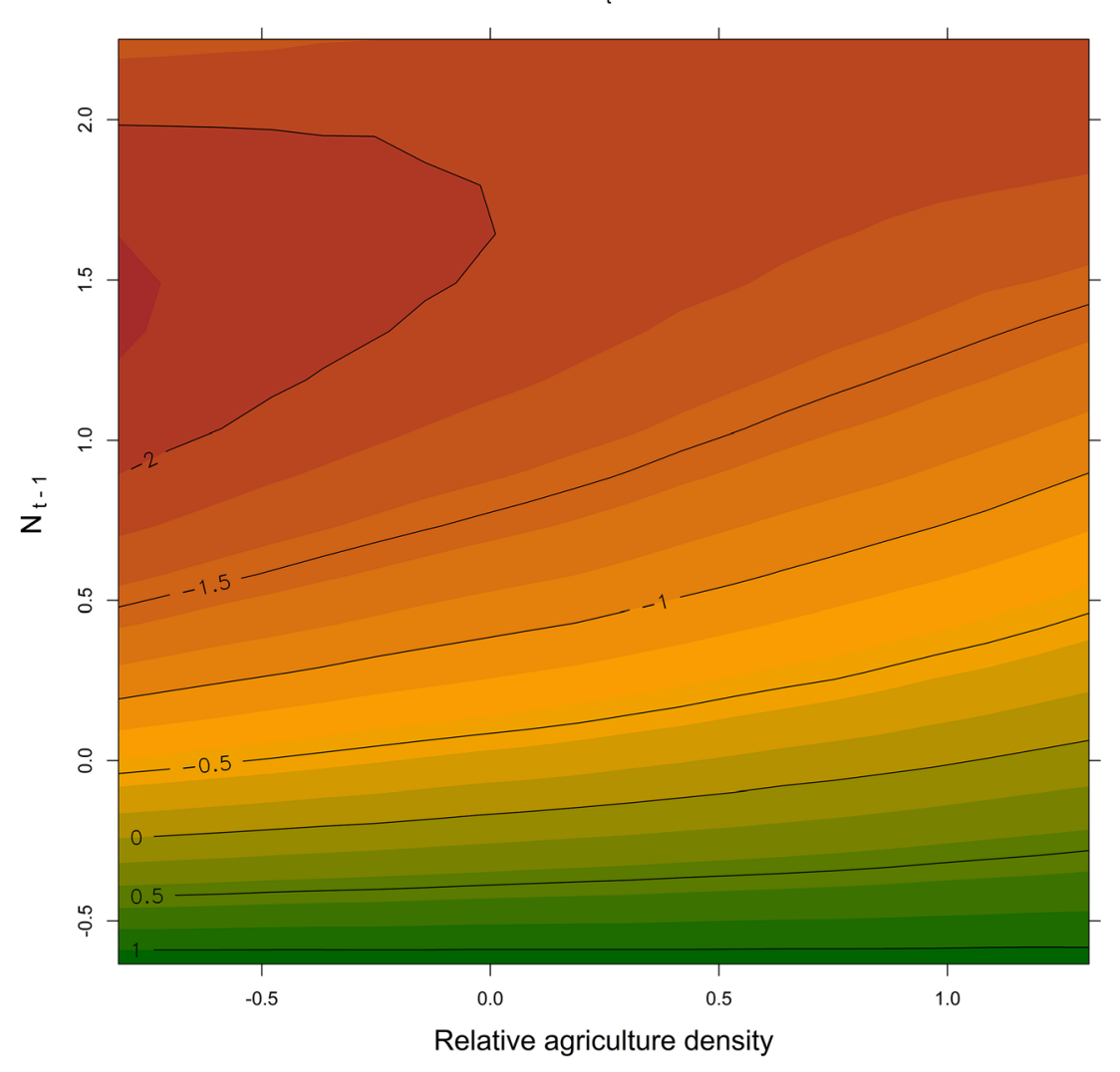

responses (i.e., aggregative and demographic) because changes in track frequencies may be due to changes in both red fox density and activity.

Density dependence across the agricultural continuum was asymmetric. As the red fox index increased, the strength of density dependence progressively relaxed with increasing relative coverage of agricultural land. This suggests that the variability in red fox is inversely related to the presence of agriculture because variable population dynamics is associated with strong density-dependent growth (Hanski 1990). Both the density and distribution of resources as well as social regulation may be underlying factors explaining this pattern. Previously, variation in space use across a large-scale productivity gradient have been observed (Walton et al. 2017), but the degree of heterogeneity in space use at smaller scales is less known, although probably similar (Kurki et al. 1998). Social regulation, due to territoriality, is one potential mechanism that may decrease with increasing territory size (Goszczyński 2002), which again is inversely related to red fox density (Trewhella et al. 1988).

In Scandinavia, predation pressure exerted on alternative prey by generalist predators (e.g., red foxes) varies in phase with the vole cycle, and this relationship is termed the alternative prey hypothesis (Hagen 1952; Angelstam et al. 1984; Panzacchi et al. 2008a). The fundamental principal is that large annual variation in the main prey, typically voles, generates predator-mediated fluctuations in alternative prey species, e.g., grouse. Due to prey switching, predation pressure on alternative prey increase during vole population declines. As vole populations increase, alternative prey is again relieved of predation pressure due to lower red fox abundance and prey switching. Provisioning red foxes with alternative foods may buffer fox population declines following the crash in the vole cycle and this may well be a mechanism causing the observed asymmetry in population regulation along the agricultural continuum. Elevated baseline populations of predators in the low phase of the prey cycle may subsequently limit cyclic amplitude in the prey population (Krebs et al. 2014). Moreover, negative feedback processes from predation in a cyclic system may also dampen prey fluctuations (Erlinge et al. 1983, 1991). Ultimately, trophic cascades driven by increased scavenger abundance, survival, and fecundity are expected implications of providing anthropogenic food subsidies (Newsome et al. 2014). Such effects on other trophic levels may, for example, involve stabilization of prey species by preventing sequential years of population growth (Hansson 1988).

Several factors may interact with habitat quality and successively modulate effects of habitat on red fox density and population dynamics in the landscape (Gorini et al. 2012). In 
spite of the potential for complex regulatory mechanisms, single-factor explanations governing red fox distribution and performance along the forest-farmland continuum is of particular interest to conservation (e.g., Tryjanowski et al. 2011) and determinants of density-dependent structure needs to be pursued in future research in general (Sibly and Hone 2002). For conservational purposes, it is important to distinguish between factors increasing the landscape's overall carrying capacity from factors that stabilize red fox population growth. Such factors are inherently different in the potential impact on alternative and incidental prey in a fluctuating environment. Reducing anthropogenic subsidization, particularly preceding and during winter may prove a successful conservation action for farmland or other species currently depressed by red fox predation.

Acknowledgments We are grateful to the Hedmark Chapter of The Norwegian Association for Hunters and Anglers and to all the volunteers collecting data.

Funding information Open Access funding provided by Inland Norway University Of Applied Sciences. The data collection was funded by the Norwegian Environment Agency. The analysis was funded by multiple sources, with JDCL and MP funded by the Norwegian Environment Agency and the Research Council of Norway (grants 183176, 212919, and 251112).

\section{Compliance with ethical standards}

Conflict of interest The authors declare that they have no conflict of interest.

\section{Appendix}

\section{Model components}

We modeled red fox abundance likelihoods with gammaPoisson (i.e., negative binomial) error distributions, whilst we modeled density-dependent growth likelihoods with Gaussian (i.e., normal) error distributions.

Abundance models:

$Y_{i} \sim$ Gamma-Poisson $\left(\mu_{i}, C_{i}\right)$

Growth models:

$Y_{i} \sim \operatorname{Normal}\left(\mu_{i}, \sigma\right)$

We fitted municipality and year as group-level effects for the linear predictors for abundance and growth models respectively. Offset for abundance models was the log of transect length $(\mathrm{km})$ and $\log$ of days since last snowfall. For abundance models, spatial autocorrelation was accounted for at the municipality level, whilst in growth models, spatial autocorrelation was accounted for between transect groups.
Abundance models:

$$
\begin{aligned}
\log \left(\mu_{i}\right)= & \log \left(\text { length }_{i}\right)+\log \left(\text { days }_{i}\right)+a_{\text {MUNICIPALITY }_{i}} \\
& +\gamma_{\text {MUNICIPALITY }_{i}}+\beta x_{i}
\end{aligned}
$$

Growth models:

$\mu_{i}=\alpha_{\mathrm{YEAR}_{i}}+\gamma_{\mathrm{TRANSGROUP}_{i}}+\beta x_{i}$

The prior distribution for the spatial autocorrelation component was formalized by a Gaussian process distribution (i.e., multivariate normal) of a $K$-dimensional ( 22 dimensions for municipalities and 255 dimensions for transect groups) matrix of zero means in order for the distribution to express the deviance from the expected mean intercept $\alpha$ in the linear predictor.

$\gamma \sim \operatorname{MVNormal}((0, \ldots, 0) K)$

The covariance matrix $K$ describing covariance between the $i_{\text {th }}$ and $j_{\text {th }}$ group-level factor was defined as the product of the maximum covariance between any two group levels $\eta^{2}$, the exponential covariance decline rate $\rho^{2}$ and squared distance $D$ between the $i_{\text {th }}$ and $j_{\text {th }}$ group-level factor. The last term, $\delta_{i j} \sigma^{2}$ (i.e., jitter term), provides additional covariance for multiple observations from the same group-level factors and was fixed to 0.01 .

$K_{i j}=\eta^{2} \exp \left(-\rho^{2} D_{i j}^{2}\right)+\delta_{i j} \sigma^{2}$

Prior distributions of hyper- and model parameters were weakly informed (i.e., flat priors). Model parameters for fixed effects $\beta$ were normally distributed and set to $\mu=0$ and $\sigma=10$ for all beta coefficient priors. The grand mean intercept parameter $\alpha$ was set to $\mu=0$ and $\sigma=1$. Scale parameter $C$ was formalized as a halfCauchy distribution with location of zero and scale of 2 (i.e., relatively wide) whilst standard deviation $\sigma$, maximum covariance $\eta^{2}$, and covariance decline rate $\rho^{2}$ were half-cauchy distributions with location of zero and scale of 1 .

$$
\begin{aligned}
& \beta \sim \operatorname{Normal}(0,10) \\
& \alpha \sim \operatorname{Normal}(0,1) \\
& C \sim \operatorname{Half-Cauchy}(0,2) \\
& \sigma \sim \operatorname{Half-Cauchy}(0,1) \\
& \rho^{2} \sim \operatorname{Half-Cauchy}(0,1) \\
& \eta^{2} \sim \operatorname{Half-Cauchy}(0,1)
\end{aligned}
$$


Fig. 7 The transect grouping prior to analysis of spatial variability. In this particular example, the first 4 years of the transect group are excluded because of only 3 years of consecutive monitoring after grouping

Fig. 8 First-order densitydependent structure $\left(r_{t}=f\left(N_{t}\right.\right.$ $\left.\left.{ }_{1}\right)+\epsilon_{t}\right)$ in the red fox population
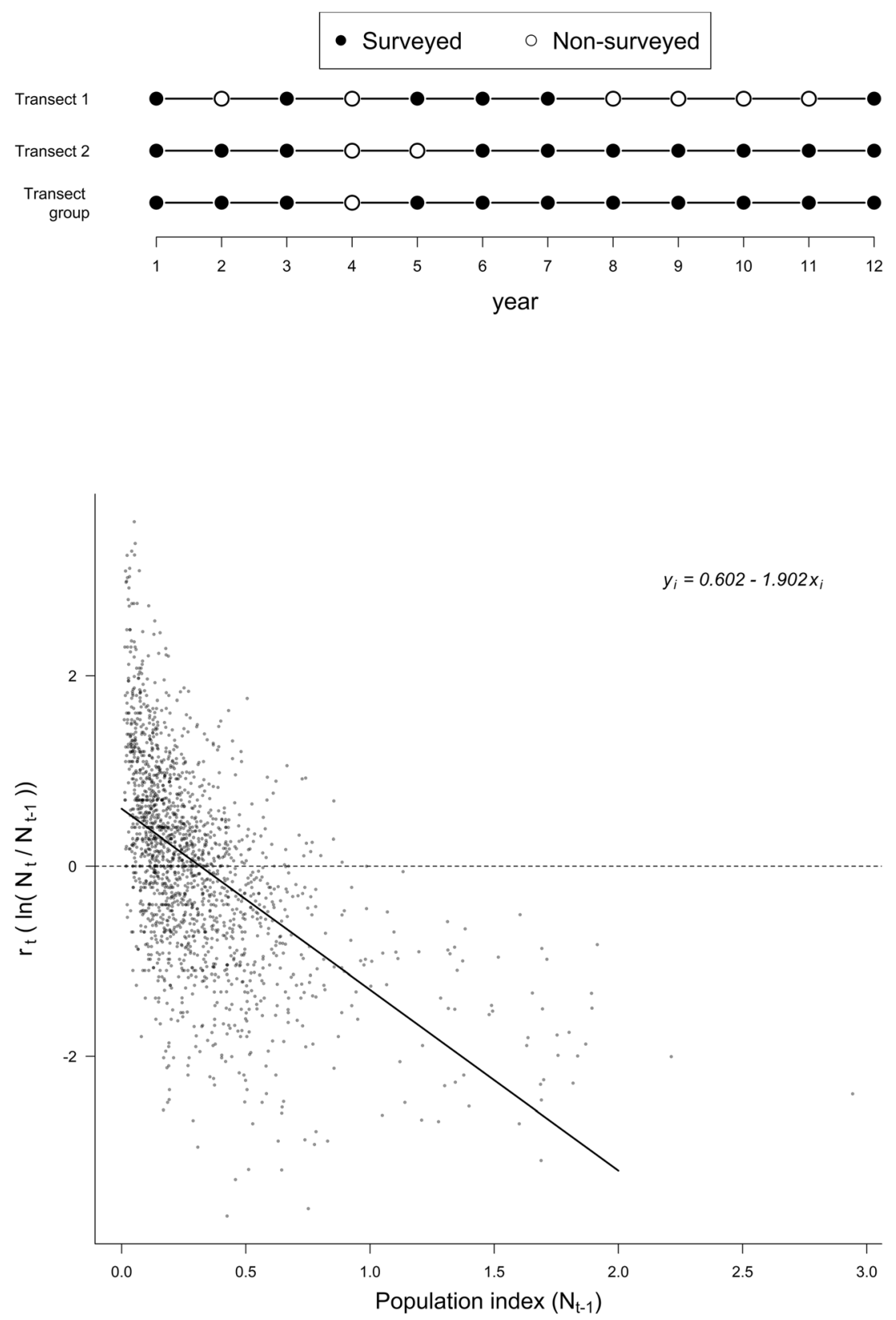
Fig. 9 Density plot of instantaneous rate of increase frequencies from the transect groups in Hedmark between 2003 and 2014. Vertical dotted line depicts the median around which values were standardized. Upper right values refer to median, standard deviation, and mean values. Minimum and maximum observed rates of increase are referred to as $r_{\min }$ and $r_{\max }$

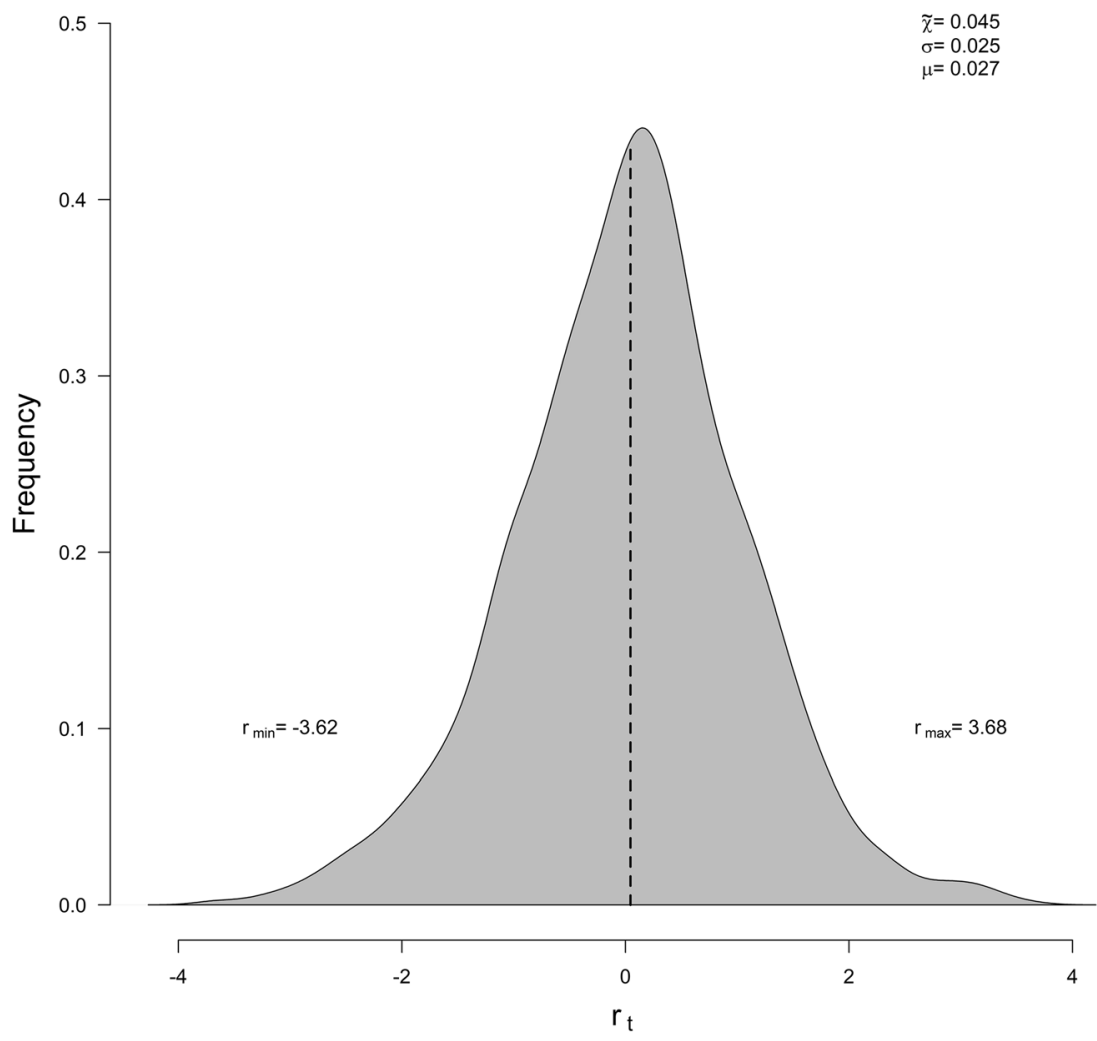

Open Access This article is licensed under a Creative Commons Attribution 4.0 International License, which permits use, sharing, adaptation, distribution and reproduction in any medium or format, as long as you give appropriate credit to the original author(s) and the source, provide a link to the Creative Commons licence, and indicate if changes were made. The images or other third party material in this article are included in the article's Creative Commons licence, unless indicated otherwise in a credit line to the material. If material is not included in the article's Creative Commons licence and your intended use is not permitted by statutory regulation or exceeds the permitted use, you will need to obtain permission directly from the copyright holder. To view a copy of this licence, visit http://creativecommons.org/licenses/by/4.0/.

\section{References}

Andrén H (1994) Effects of habitat fragmentation on birds and mammals in landscapes with different proportions of suitable habitat: a review. Oikos 71:355. https://doi.org/10.2307/3545823

Angelstam P, Lindström E, Widén P (1984) Role of predation in shortterm population fluctuations of some birds and mammals in Fennoscandia. Oecologia 62:199-208

Baddeley AJ, Rubak E, Turner R (2016) Spatial point patterns: methodology and applications with $\mathrm{R}$

Baines D, Aebischer NJ, Macleod A (2016) Increased mammalian predators and climate change predict declines in breeding success and density of capercaillie Tetrao urogallus, an old stand specialist, in fragmented Scottish forests. Biodivers Conserv 25:2171-2186. https://doi.org/10.1007/s10531-016-1185-8

Bartoń K, Zalewski A (2007) Winter severity limits red fox populations in Eurasia. Glob Ecol Biogeogr 16:281-289
Berryman A, Turchin P (2001) Identifying the density-dependent structure underlying ecological time series. Oikos 92:265-270. https:// doi.org/10.1034/j.1600-0706.2001.920208.x

Bjørlo B, Snellingen Bye A, Rognstad O (2019) Statistics Norway. https://www.ssb.no/jord-skog-jakt-og-fiskeri/statistikker/stjord. Accessed 5 Dec 2019

Bogdziewicz M, Zwolak R (2013) Responses of small mammals to clearcutting in temperate and boreal forests of Europe: a meta-analysis and review. Eur J For Res 133:1-11. https://doi.org/10.1007/ s10342-013-0726-x

Breisjøberget JI, Odden M, Wegge P, Zimmermann B, Andreassen H (2018) The alternative prey hypothesis revisited: still valid for willow ptarmigan population dynamics. PLoS One 13:e197289. https://doi.org/10.1371/journal.pone.0197289

Cagnacci F, Lovari S, Meriggi A (2003) Carrion dependence and food habits of the red fox in an Alpine area. Ital J Zool 70:31-38

Carricondo-Sanchez D, Samelius G, Willebrand O, Willebrand T (2016) Spatial and temporal variation in the distribution and abundance of red foxes in the tundra and taiga of northern Sweden. Eur J Wildl Res 62:211-218

Cavallini P, Lovari S (1991) Environmental factors influencing the use of habitat in the red fox, Vulpes vulpes. J Zool 223:323-339

Christiansen E (1979) Skog- og jordbruk, smågnagere og rev. Tidsskr Skogbr 87:115-119 In Norwegian

DeVault T, Jr OR, Shivik J (2003) Scavenging by vertebrates: behavioral, ecological, and evolutionary perspectives on an important energy transfer pathway in terrestrial ecosystems. Oikos 102:225-234

Elmhagen B, Kindberg J, Hellström P, Angerbjörn A (2015) A boreal invasion in response to climate change? Range shifts and community effects in the borderland between forest and tundra. Ambio 44:39-50

Englund J (1980a) Population dynamics of the red fox (Vulpes vulpes L., 1758) in Sweden. In: The red fox. pp 107-121 
Englund J (1980b) Yearly variations of recovery and dispersal rates of fox cubs tagged in Swedish coniferous forests. In: The red fox. Springer Netherlands, Dordrecht, pp 195-207

Erlinge S, Göransson G, Hansson L (1983) Predation as a regulating factor on small rodent populations in southern Sweden. Oikos 40:36-52

Erlinge S, Agrell J, Nelson J, Sandell M (1991) Why are some microtine populations cyclic while others are not? Acta Theriol (Warsz) 36:63-71

ESRI INC (2011) ArcGIS

Fancourt BA, Hawkins CE, Cameron EZ et al (2015) Devil declines and catastrophic cascades: is mesopredator release of feral cats inhibiting recovery of the eastern quoll? PLoS One 10. https://doi.org/10.1371/ journal.pone. 0119303

Foley JA, DeFries R, Asner GP et al (2005) Global consequences of land use. Science (80- ) 309:570-574

Frafjord K, Becker D, Angerbjorn A (1989) Interactions between arctic and red foxes in Scandinavia - predation and aggression. Arctic 42: 354-356. https://doi.org/10.2307/40510856

Gelman A, Su Y-S (2016) Data analysis using regression and multilevel/ hierarchical models - R package version 1.9-3

Gomo G, Mattisson J, Hagen BR, Moa PF, Willebrand T (2017) Scavenging on a pulsed resource: quality matters for corvids but density for mammals. BMC Ecol 17:22. https://doi.org/10.1186/ s12898-017-0132-1

Gorini L, Linnell JDC, May R et al (2012) Habitat heterogeneity and mammalian predator-prey interactions: predator-prey interactions in a spatial world. Mammal Rev 42:55-77. https://doi.org/10.1111/ j.1365-2907.2011.00189.x

Gosselink TE, Van Deelen TR, Warner RE, Joselyn MG (2003) Temporal habitat partitioning and spatial use of coyotes and red foxes in EastCentral Illinois. J Wildl Manag 67:90. https://doi.org/10.2307/3803065

Goszczyński J (2002) Home ranges in red fox: territoriality diminishes with increasing area. Acta Theriol (Warsz) 47:103-114. https://doi. org/10.1007/BF03192482

Güthlin D, Storch I, Küchenhoff H (2013) Landscape variables associated with relative abundance of generalist mesopredators. Landsc Ecol 28:1687-1696. https://doi.org/10.1007/s10980-013-9911-z

Hagen Y (1952) Rovfuglene Og Viltpleien, 1st edn. Gyldendal, Oslo (in Norwegian)

Halpin M, Bissonette J (1988) Influence of snow depth on prey availability and habitat use by red fox. Can J Zool 66:587-592

Hanski I (1990) Density dependence, regulation and variability in animal populations. Philos Trans R Soc B Biol Sci 330:141-150. https:// doi.org/10.1098/rstb.1990.0188

Hansson L (1988) The domestic cat as a possible modifier of vole dynamics. Mammalia 52:159-164

Harris S (1981) An estimation of the number of foxes (Vulpes vulpes) in the city of Bristol, and some possible factors affecting their distribution. J Appl Ecol 18:455. https://doi.org/10.2307/2402406

Henden JA, Ims RA, Yoccoz NG et al (2010) Strength of asymmetric competition between predators in food webs ruled by fluctuating prey: the case of foxes in tundra. Oikos 119:27-34. https://doi.org/ 10.1111/j.1600-0706.2009.17604.x

Henden JA, Stien A, Bårdsen BJ et al (2014) Community-wide mesocarnivore response to partial ungulate migration. J Appl Ecol 51:1525-1533. https://doi.org/10.1111/1365-2664.12328

Henttonen H (1989) Does an increase in the rodent and predator densities, resulting from modern forestry, contribute to the long-term decline in Finnish tetraonids? Suom Riista 35:83-90

Hersteinsson P, MacDonald DW (1992) Interspecific competition and the geographical distribution of red and Arctic foxes Vulpes Vulpes and Alopex lagopus. Oikos 64:505-515. https://doi.org/10.2307/3545168

Hijmans RJ (2016) raster: geographic data analysis and modeling

Hone J (1999) On rate of increase (r): patterns of variation in Autralian mammals and the implications for wildlife management. J Appl Ecol 36:709-718
Jędrzejewski W, Jędrzejewska B (1992) Foraging and diet of the red fox Vulpes vulpes in relation to variable food resources in Biatowieza National Park, Poland. Ecography (Cop) 15:212-220

Kämmerle JL, Coppes J, Ciuti S et al (2017) Range loss of a threatened grouse species is related to the relative abundance of a mesopredator. Ecosphere 8:e01934. https://doi.org/10.1002/ecs2.1934

Kauhala K, Laukkanen P, Von Rége I (1998) Summer food composition and food niche overlap of the raccoon dog, red fox and badger in Finland. Ecography (Cop) 21:457-463. https://doi.org/10.1111/j. 1600-0587.1998.tb00436.x

Kauhala K, Helle P, Helle E (2000) Predator control and the density and reproductive success of grouse populations in Finland. Ecography (Cop) 23:161-168. https://doi.org/10.2307/3683017

Kawaguchi T, Desrochers A, Bastien H (2015) Snow tracking and trapping harvest as reliable sources for inferring abundance: a 9-year comparison. Northeast Nat 22:798-811. https://doi.org/10.1656/045.022.0413

Killengreen ST, Lecomte N, Ehrich D, Schott T, Yoccoz NG, Ims RA (2011) The importance of marine vs. human-induced subsidies in the maintenance of an expanding mesocarnivore in the arctic tundra. J Anim Ecol 80:1049-1060. https://doi.org/10.1111/j.1365-2656.2011.01840.x

Krebs CJ, Bryant J, Kielland K et al (2014) What factors determine cyclic amplitude in the snowshoe hare (Lepus americanus) cycle? Can J Zool 92:1039-1048. https://doi.org/10.1139/cjz-2014-0159

Kurki S, Nikula A, Helle P, Linden H (1998) Abundances of red fox and pine marten in relation to the composition of boreal forest landscapes. J Anim Ecol 67:874-886. https://doi.org/10.1046/j.13652656.1998.6760874.x

Lapoint SD, Belant JL, Kays RW (2015) Mesopredator release facilitates range expansion in fisher. Anim Conserv 18:50-61. https://doi.org/ 10.1111/acv. 12138

Lindén H (1988) Latitudinal gradients in predator-prey interactions, cyclicity and synchronism in voles and small game populations in Finland. Oikos 52:341-349

Lindström E (1982) Population ecology of the red fox (Vulpes vulpes L.) in relation to food supply. University of Stockholm

Lindstrom ER, Andren H, Angelstam P et al (1994) Disease reveals the predators: sarcoptic mange, red fox predation, and prey populations. Ecology 75:1042-1049. https://doi.org/10.2307/1939428

Linnell JDC, Odden J, Pedersen V, Andersen R (1998) Records of intra-guild predation by Eurasian lynx, Lynx lynx. Can F Nat 112:707-708

Linnell JDC, Fiske P, Odden J et al (2007) An evaluation of structured snow-track surveys to monitor Eurasian lynx Lynx lynx populations. Wildl Biol 13:456-466. https://doi.org/10.2981/0909-6396(2007) 13[456:AEOSSS]2.0.CO;2

Loison A, Langvatn R (1998) Short- and long-term effects of winter and spring weather on growth and survival of red deer in Norway. Oecologia 116:489-500. https://doi.org/10.1007/s004420050614

Marcström V, Kenward R, Engren E (1988) The impact of predation on boreal tetraonids during vole cycles: an experimental study. J Anim Ecol 57:859-872

McElreath R (2016) Statistical rethinking: a Bayesian course with examples in R and Stan. CRC-Press

McKinney M (2002) Urbanization, biodiversity, and conservation the impacts of urbanization on native species are poorly studied, but educating a highly urbanized human population. Bioscience 52:883-890

McKinnon L, Berteaux D, Gauthier G, Bêty J (2013) Predator-mediated interactions between preferred, alternative and incidental prey in the arctic tundra. Oikos 122:1042-1048. https://doi.org/10.1111/j.16000706.2012.20708.x

Miljødirektoratet, Naturdata (2016) Hjorteviltregisteret. www. hjorteviltregisteret.no

Milner JM, Bonenfant C, Mysterud A et al (2006) Temporal and spatial development of red deer harvesting in Europe: biological and cultural factors. J Appl Ecol 43:721-734. https://doi.org/10.1111/j. 1365-2664.2006.01183.x 
Moran PAP (1950) Notes on continuous stochastic phenomena. Biometrika 37:17-23. https://doi.org/10.2307/2332142

Needham R, Odden M, Lundstadsveen SK, Wegge P (2014) Seasonal diets of red foxes in a boreal forest with a dense population of moose: the importance of winter scavenging. Acta Theriol (Warsz) 59:391-398. https://doi.org/10.1007/s13364-014-0188-7

Newsome TM, Dellinger JA, Pavey CR et al (2014) The ecological effects of providing resource subsidies to predators. Glob Ecol Biogeogr 24:1-11. https://doi.org/10.1111/geb.12236

Odden J, Linnell JDC, Andersen R (2006) Diet of Eurasian lynx, Lynx lynx, in the boreal forest of southeastern Norway: the relative importance of livestock and hares at low roe deer density. Eur J Wildl Res 52:237-244. https://doi.org/10.1007/s10344-006-0052-4

Ordiz A, Milleret C, Kindberg J et al (2015) Wolves, people, and brown bears influence the expansion of the recolonizing wolf population in Scandinavia. Ecosphere 6:art284. https://doi.org/10.1890/ES15-00243.1

Panek M, Bresinski W (2002) Red fox Vulpes vulpes density and habitat use in a rural area of western Poland in the end of 1990s, compared with the turn of 1970s. Acta Theriol (Warsz) 47:433-442. https:// doi.org/10.1007/bf03192468

Panzacchi M, Linnell JDC, Odden J et al (2008a) When a generalist becomes a specialist: patterns of red fox predation on roe deer fawns under contrasting conditions. Can J Zool 86:116-126. https://doi. org/10.1139/Z07-120

Panzacchi M, Linnell JDC, Serrao G, Eie S, Odden M, Odden J, Andersen R (2008b) Evaluation of the importance of roe deer fawns in the spring-summer diet of red foxes in southeastern Norway. Ecol Res 23:889-896. https://doi.org/10.1007/s11284-007-0452-2

Panzacchi M, Linnell JDC, Odden M, Odden J, Andersen R (2009) Habitat and roe deer fawn vulnerability to red fox predation. $\mathrm{J}$ Anim Ecol 78:1124-1133. https://doi.org/10.1111/j.1365-2656. 2009.01584.x

Panzacchi M, Linnell JDC, Melis C et al (2010) Effect of land-use on small mammal abundance and diversity in a forest-farmland mosaic landscape in south-eastern Norway. For Ecol Manag 259:1536 1545. https://doi.org/10.1016/j.foreco.2010.01.030

Prugh LR, Stoner CJ, Clinton WE et al (2009) The rise of the mesopredator. Bioscience 59:779-791. https://doi.org/10.1525/bio. 2009.59.9.9

Pulliainen E (1981) A transect survey of small land carnivore and red fox populations on a subartic fell in Finnish Forest Lapland over 13 winters. Ann Zool Fenn 18:270-278

R Core Team (2016) R: a language and environment for statistical computing

Rosalino LM, Sousa M, Pedroso NM et al (2010) The influence of food resources on red fox local distribution in a mountain area of the Western Mediterranean. Vie milieu - Life Environ 60:1-7

Selås V, Vik JO (2006) Possible impact of snow depth and ungulate carcasses on red fox (Vulpes vulpes) populations in Norway, 1897 1976. J Zool 269:299-308. https://doi.org/10.1111/j.1469-7998. 2006.00048.x

Selås V, Johnsen BS, Eide NE (2010) Arctic fox Vulpes lagopus den use in relation to altitude and human infrastructure. Wildl Biol 16:107112. https://doi.org/10.2981/09-023

Selås V, Sonerud GA, Framstad E, Kålås JA, Kobro S, Pedersen HB, Spidsø TK, Wiig Ø (2011) Climate change in Norway: warm summers limit grouse reproduction. Popul Ecol 53:361-371. https://doi. org/10.1007/s10144-010-0255-0

Sibly RM, Hone J (2002) Population growth rate and its determinants: an overview. Philos Trans R Soc B Biol Sci 357:1153-1170. https:// doi.org/10.1098/rstb.2002.1117

Sidorovich V, Sidorovich A, Izotova I (2006) Variations in the diet and population density of the red fox Vulpes vulpes in the mixed woodlands of northern Belarus. Mamm Biol 71:74-89

Silverman BW (1986) Density estimation for statistics and data analysis. Chapman and Hall
Skara AB, Steinset TA (2016) Statistics Norway. https://www.ssb.no/ jord-skog-jakt-og-fiskeri/statistikker/elgjakt. Accessed 3 Nov 2016

Smedshaug C, Selås V, Lund S, Sonerud G (1999) The effect of a natural reduction of red fox Vulpes vulpes on small game hunting bags in Norway. Wildl Biol 5:157-166

Statistics Norway (2016) Statistics Norway. https://www.ssb.no/ statistikkbanken/selectvarval/Define.asp? subjectcode $=$ $\&$ ProductId $=\&$ MainTable $=$ Smaavilt $2 \& n v l=\&$ PLanguage $=$ $0 \&$ nyTmp Var=true \&CMSSubjectArea $=$ jord-skog-jakt-ogfiskeri\&KortNavnWeb=srjakt\&StatVariant $=\&$ checked=true. Accessed 28 Mar 2016

Storch I, Lindström E, de Jounge J (1990) Diet and habitat selection of the pine marten in relation to competition with the red fox. Acta Theriol (Warsz) 35:311-320

Stubsjøen T, Sæther B-E, Solberg EJ et al (2000) Moose (Alces alces ) survival in three populations in northern Norway. Can J Zool 78: 1822-1830. https://doi.org/10.1139/z00-132

The Norwegian Mapping Authority (2017) The Norwegian Mapping Authority. http://kartverket.no/en/. Accessed 2 Feb 2017

Thompson ID, Davidson IJ, O’Donnell S, Brazeau F (1989) Use of track transects to measure the relative occurrence of some boreal mammals in uncut forest and regeneration stands. Can J Zool 67:18161823. https://doi.org/10.1139/z89-258

Thorson JT, Skaug H, Kristensen K, Shelton AO, Ward EJ, Harms JH, Benante JA (2015) The importance of spatial models for estimating the strength of density dependence. Ecology 96:1202-1212. https:// doi.org/10.1890/14-0739.1

Tjernberg M (1981) Diet of the golden eagle Aquila chrysaetos during the breeding season in Sweden. Ecography (Cop) 4:12-19. https://doi. org/10.1111/j.1600-0587.1981.tb00975.x

Tovmo M, Mattisson J, Kleven O, Brøseth H (2016) Overvaking av kongeørn i Noreg 2015. Resultat frå 12 intensivt overvaka område, NINA Rappo. Trondheim - In Norwegian

Trewhella WJ, Harris S, McAllister FE (1988) Dispersal distance, homerange size and population density in the red fox (Vulpes vulpes): a quantitative analysis. J Appl Ecol 25:423-434

Tryjanowski P, Hartel T, Báldi A et al (2011) Conservation of farmland birds faces different challenges in Western and Central-Eastern Europe. Acta Ornithol 46:1-12. https://doi.org/10.3161/000164511X589857

Turchin P (2003) Complex population dynamics: a theoretical/empirical synthesis. Princeton University Press

Vos A (1995) Population dynamics of the red fox (Vulpes vulpes) after the disappearance of rabies in county Garmisch-Partenkirchen, Germany, 1987-1992. Ann Zool Fenn 32:93-97

Vuorisalo T, Talvitie K, Kauhala K et al (2014) Urban red foxes (Vulpes vulpes L.) in Finland: a historical perspective. Landsc Urban Plan 124:109-117. https://doi.org/10.1016/j.landurbplan.2013.12.002

Walther G-R, Post E, Convey P, Menzel A, Parmesan C, Beebee TJ, Fromentin JM, Hoegh-Guldberg O, Bairlein F (2002) Ecological responses to recent climate change. Nature 416:389-395. https:// doi.org/10.1038/416389a

Walton Z, Samelius G, Odden M, Willebrand T (2017) Variation in home range size of red foxes Vulpes vulpes along a gradient of productivity and human landscape alteration. PLoS One:12. https://doi.org/10. 1371/journal.pone.0175291

Watanabe S (2010) Asymptotic equivalence of Bayes cross validation and widely applicable information criterion in singular learning theory. J Mach Learn Res 11:3571-3594

Willebrand T, Willebrand S, Jahren T, Marcström V (2017) Snow tracking reveals different foraging patterns of red foxes and pine martens. Mammal Res 62:331-340. https://doi.org/10.1007/s13364-017-0332-2

Publisher's note Springer Nature remains neutral with regard to jurisdictional claims in published maps and institutional affiliations. 